\title{
Analysis on Pollution Hazards and Recycling Strategies of Logistics Packaging Wastes of E-Commerce Enterprises
}

\section{Zhongchao Hao}

Department of Information Engineering, Changzhou Institute of Industry Technology, Changzhou 213164, China

$\dagger$ Corresponding author: Zhongchao Hao; haozc@ @iit.edu.cn

\section{Nat. Env. \& Poll. Tech.}

Website: www.neptjournal.com

Received: 16-04-2021

Revised: $19-06-2021$

Accepted: 28-06-2021

\section{Key Words:}

E-commerce enterprise

Logistics wastes

Package pollution

Recycling strategies

SEM

\begin{abstract}
The emergence of China's e-commerce industry leads to the rapid expansion of the express delivery industry, and the environmental pollution problem triggered by the express packaging wastes has become increasingly critical, severely impacting human health and sustainable social development. The literature regarding the pollution and recycling strategies of e-commerce logistics packaging wastes was first complied with and summarized in this work. Then, the research hypothesis of multi-subject (e-commerce enterprise, government, and third-party enterprises) in the recycling of e-commerce logistics packaging wastes was established. Finally, the effect of multi-subject participation in the recycling of e-logistics packaging wastes was surveyed via questionnaires using structural equation modeling. Results demonstrate that under the background of high-speed e-commerce development, the package pollution problem has become an important problem influencing environmental pollution in various countries across the world. The overall Cronbach's alpha value of the questionnaires was 0.903 , indicating good reliability. The observable variable- standard factor loading coefficient, was always greater than 0.5 , indicating that the construct validity was accurate. Third-party and e-commerce enterprises played a significant positive role in the recycling effect of e-commerce logistics packaging wastes, with regression coefficients of 1.981 and 0.575 , respectively. The government did not show any obvious influence on the recycling effect of e-commerce logistics packaging wastes. The pollution hazards of logistics packaging wastes of e-commerce enterprises can be effectively mitigated if e-commerce enterprises lead the green consumption needs, the government accelerates the perfection of laws and regulations related to the e-commerce logistics packaging, and a thirdparty professional recycling system is established, among others things. The study results will be of great reference significance for deeply analyzing the problems existing in the current express package pollution control and their causes, exploring the factors influencing the recycling effect of e-commerce logistics packaging wastes and enriching the multi-subject recycling strategies for express package pollution.
\end{abstract}

\section{INTRODUCTION}

With the popularization and rapid development of the internet, the emerging consumption model-online shopping has been increasingly favored and gradually become an important constituent part of people's daily life. Fig. 1 shows that China's express business volume in 2010 reached $2,340,000,000$, and the expression business income was RMB 57,460,000,000. The express business volume is increasing in consecutive years owing to the growing popularity of online shopping. Up to 2019, the express business volume was $63,520,000,000$, and the expression business income was RMB 749,780,000,000, which increased by 27.15 and 13.05 times, respectively. However, behind the prosperous development of the express delivery industry is the great demand for express packaging materials, which, in China, mainly include plastic bags, woven bags, express waybills, packaging boxes, packaging tapes, envelopes, and internal fillers. These packaging materials will result in certain environmental problems in the manufacturing and terminal treatment links. Most express packages are disposable, meaning that they will no longer serve as packaging ones after the express transportation is completed and will become packaging wastes without use-value.

In certain big cities in China, the increment in express packaging wastes already accounts for the vast majority of the increase in household wastes. The recycling rate of express packaging wastes is lower than the massive express packaging wastes. The overall recycling rate of express packaging wastes is low in China. Given that the proportion of green packaging materials currently used in the express delivery industry is low, most plastic bags and scotch tapes are non-degradable materials made of polyvinyl chloride (PVC), which, if arbitrarily discarded, will pollute the environment. 


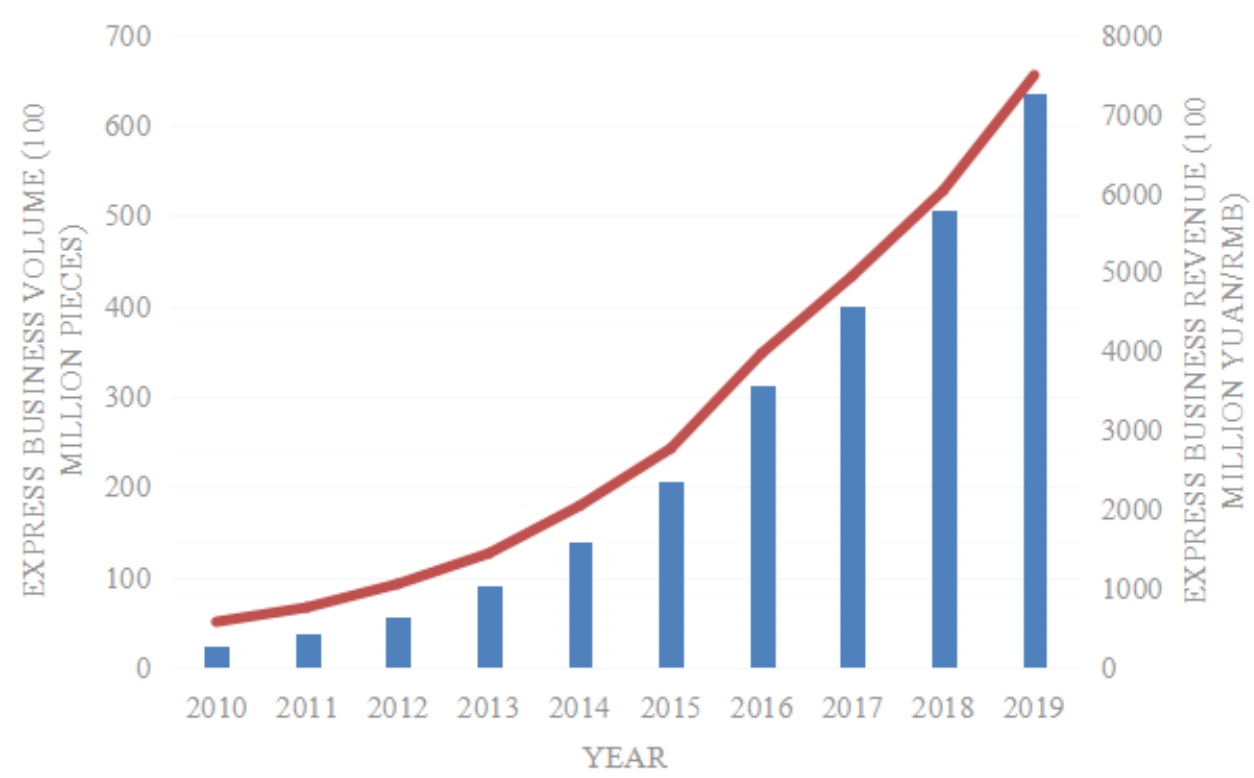

Fig. 1: China's express business volumes and incomes during 2010-2019.

(Data derived from Report on China Express Development Index [2020])

The express packages are faced with recycling difficulty, and a considerable number of packages are directly burnt or landfilled without the recycling link, leading to serious environmental pollution. In the era featured by the rapid development of online shopping and express delivery industry, the pollution hazards of express packages must be analyzed, and the multi-subject recycling strategies for the e-commerce express packaging wastes must be systematically explored.

\section{OVERVIEW OF THE STUDY AREA}

The environmental destruction and waste of resources, which are induced by express packages, have become more serious with the rapid increase in the express business volume in China. The multi-subject recycling strategy for express packages has become a resource, environmental protection and social problem to be solved urgently. The recycling strategy, logistics pattern, and package design have been mainly analyzed with respect to the recycling of e-commerce logistics wastes. Bamberg (2003) analyzed the decisions of students with high and weak environmental awareness in applying for the information manual of green electronic products. The author stated that the recycling willingness was affected by the richness level of environmental knowledge. Robinson et al. (2005) surveyed two large families, namely, Royal Kensington and Chelsea in Great London, and pointed out that the large-scale propaganda of environmental protection could effectively improve the recycling effect; more residents were required to trust in the necessity of garbage recycling. Kelly et al. (2006) surveyed 1400 students and staff in Massey University, New Zealand and stated that the recycling behavior was significantly correlated with two factors: attitude toward recycling and occupational identity. Feng et al. (2006) studied two problems: design and coordination of reverse supply chain, traditional channel, and online recycling channel. The results showed that from the perspective of the recyclable distributor and system, the performance of the double-loop channel was always superior to that of the single-loop channel. Knussen et al. (2008) conducted a questionnaire survey on 252 participants from Scotland, Britain and thought that both past behaviors and lack of habit significantly contributed to the diversity in recycling willingness. Lin et al. (2009) used the analytical hierarchy process to analyze the consumer willingness to recycle discarded home appliances and proposed measures that could strengthen consumer willingness to take a part in e-waste recycling. Veiga (2013) analyzed the effect of compulsory waste control and recycling policy in Brazil; The results manifested that the reverse logistics project achieved an overall success, but its efficiency was not high for small-sized rural communities. Wang et al. (2016) explored the factors deciding the residential e-waste recycling behavioral intention in China; the author stated that the cognition of informal recycling influenced residential behavioral intention, and 
the standardization and propaganda had positive influences on the cognition of informal recycling. Yamaguchi et al. (2016) used the contingent value method to assess consumer preferences for low-quality packaging. The results showed that economic means could influence consumers to purchase products with simplified packages because high disposal costs reduced the attraction of product sources. Klaiman et al. (2016) assessed the consumer willingness to pay (WTP) for packaging materials and recoverability of beverages via a discrete choice experiment. The results showed that the packaging materials enjoying the maximum consumer WTP were the plastic package, followed by glass, carton, and aluminum. Bai et al. (2018) explored the pattern and trend of recycling attitudes and behaviors of Chinese consumers and pointed out that economic incentive, recycling convenience, and information security were the primary requirements of consumers for recycling smartphones. From the perspective of university green education, Yu et al. (2019) corrected and verified the citizens' pro-environmental behavioral model and stated that green education could improve citizens' environmental awareness and generate the intentions of environmental sustainability and cyclic utilization. Taking Hangzhou City, for example, Pei (2019) discovered that the neighborhood relationship and community attachment generated direct positive influences on residents' willingness to recycle wastes. Arain et al.(2020) deemed that America lacked a set of unified e-waste recycling methods, which led to a low e-waste recycling rate among consumers and evaluated the influences of consumer behaviors on e-waste recycling. The results showed that the primary factors influencing consumer decisions are consumers' poor understanding of products and disposal sites and uneasy acquisition of recycling facilities within a reasonable distance. Aboelmaged (2020) believed that young consumers played an important role in the generation of e-waste problems and used the partial least squares SEM to perform a multivariate statistical analysis of survey data. The survey results showed that the recycling habit and consciousness generated significant effects on young people's willingness to recycle e-waste. Existing research literature has shown that the express package pollution problem under the rapid development of e-commerce has raised wide concern in domestic and foreign academic circles. However, the recycling strategies for express packaging wastes have been less involved, and the few studies regarding this have not been systematic and deep enough. The SEM was used in this study to empirically study the effect of multi-subject participation in express package recycling by analyzing the pollution hazards of e-commerce express packages. The corresponding countermeasures were proposed from the angle of e-commerce logistics wastes to provide a certain reference for the practice of express package pollution control under the high-speed e-commerce development in China.

\section{POLLUTION HAZARDS OF E-COMMERCE PACKAGING WASTES}

\section{Water Pollution Caused by Package Production}

Express package pollution mainly refers to the pollution generated in the manufacturing and terminal treatment process of express packaging materials. In daily life, express packaging bags are mostly processed from domestic and chemical wastes, which may contain a large quantity of residues of toxic and harmful substances. During the recycling, the raw wastes should be first washed, while most reprocessed plastic enterprises are family workshop-style small enterprises with incomplete pollution discharge equipment and arbitrary sewage discharge, thus leading to water resource pollution.

\section{Waste Pollution Caused by the Package Treatment Link}

In China's express delivery industry, the overall recycling rate of package wastes is low, and plastic bags and scotch tapes are mostly non-degradable packaging materials made of PVC, which is mainly disposed of through landfills or burning. However, the waste PVC, if buried in soil, can be completely degraded only after 100 years, which will result in soil hardening and reduce the nutrient substances in soil, thus impeding the plant growth. The degraded plastic packages will also enter the groundwater system by forming tiny plastic particles, intrude into the food chain of human beings, and harm human health. When these degraded packages are inappropriately burnt, solid-state pollution will be transformed into gaseous-state pollution or pollution in other forms and continue to pollute the environment.

\section{MODEL PROFILE AND HYPOTHESIS SETTING}

\section{Structural Equation Modeling (SEM)}

The structural equation reflecting the causal relationship between the measurable variable and latent variable was established according to SEM. This equation consists of two parts: measurement and structural equations. The specific model can be expressed as follows:

Measurement equation: $\mathrm{X}=\Lambda_{\mathrm{x}} \xi+\delta, \mathrm{Y}=\Lambda_{\mathrm{y}} \eta+\varepsilon \ldots(1)$

Structural equation: $\eta=\gamma \xi+\beta \eta+\zeta$

where $\mathrm{X}$ is the vector consisting of exogenous indexes; $\mathrm{Y}$ denotes the vector composed of endogenous indexes; $\delta$ and $\varepsilon$ represent the measurement errors of $\mathrm{X}$ and $\mathrm{Y}$, respectively; $\Lambda_{\mathrm{x}}$ expresses the relationship between the index $\mathrm{X}$ and latent variable $\xi ; \Lambda_{\mathrm{y}}$ is the relationship between the 
index $\mathrm{Y}$ and latent variable $\eta ; \xi$ and $\eta$ stand for exogenous and endogenous latent variables, respectively; $\gamma$ and $\beta$ are the structural coefficient matrixes that reflect the interaction between exogenous $\xi$ and endogenous $\eta$ latent variables; and $\zeta$ is the residual error term.

\section{Hypothesis Setting}

According to the research results of several scholars worldwide, the multiple subjects that participate in the recycling of express packages were defined as e-commerce and third-party recycling enterprises. The recycling effect was taken as a dependent variable, and the hypotheses were made, as illustrated in Table 1.

\section{EMPIRICAL STUDY}

\section{Reliability and Validity Analysis of Samples}

The questionnaire respondents were managers of micro, small, and medium-sized e-commerce enterprises, government officials from the e-commerce and environmental protection department, and managers from third-party professional garbage recycling institutions. The investigation was conducted by combining interviews and questionnaires.
The questionnaires were distributed online and offline. A total of 394 questionnaires were recovered, where 362 were valid questionnaires, and the effective recycling rate was $91.9 \%$. The reliability analysis was performed for the 11 observable variables of four latent variables-recycling by e-commerce enterprises, government recycling, third-party recycling, and recycling effect-via statistical software SPSS22.0 to further confirm the reliability and validity of questionnaires (Table 2). The overall Cronbach's $a$ value of the questionnaires was 0.903 , and those of the four latent variables were $0.702,0.614,0.677$, and 0.500 , respectively, indicating favorable consistency of measurement indexes and strong questionnaire homogeneity. Meanwhile, the standard factor loading coefficients of all observable variables were greater than 0.5 , manifesting a good construct validity of each latent variable (Table 3 ).

\section{Exploratory Factor Analysis}

First, the correlation coefficient matrix of the observable variables in the structural equation was calculated. The results showed that most correlation coefficient values exceeded the critical value (0.396). Second, the KMO sample measurement and Bartlett spherical test analysis were conducted for the survey data via SPSS22.0. According to the results, the

Table 1: Hypothesis setting for the effect of multi-subject participation in the recycling of express packages

\begin{tabular}{ll}
\hline Code number & Content \\
\hline H1 & Recycling of express package wastes by e-commerce enterprises has a significant positive influence on the recycling effect. \\
H2 & The government recycling of express package wastes generates a remarkable positive influence on the recycling effect. \\
H3 & $\begin{array}{l}\text { The recycling effect is positively influenced at a significant level by the participation of third-party enterprises in the recycling } \\
\text { of express package wastes. }\end{array}$ \\
\hline
\end{tabular}

Table 2: Sample reliability and validity and factor analytical results.

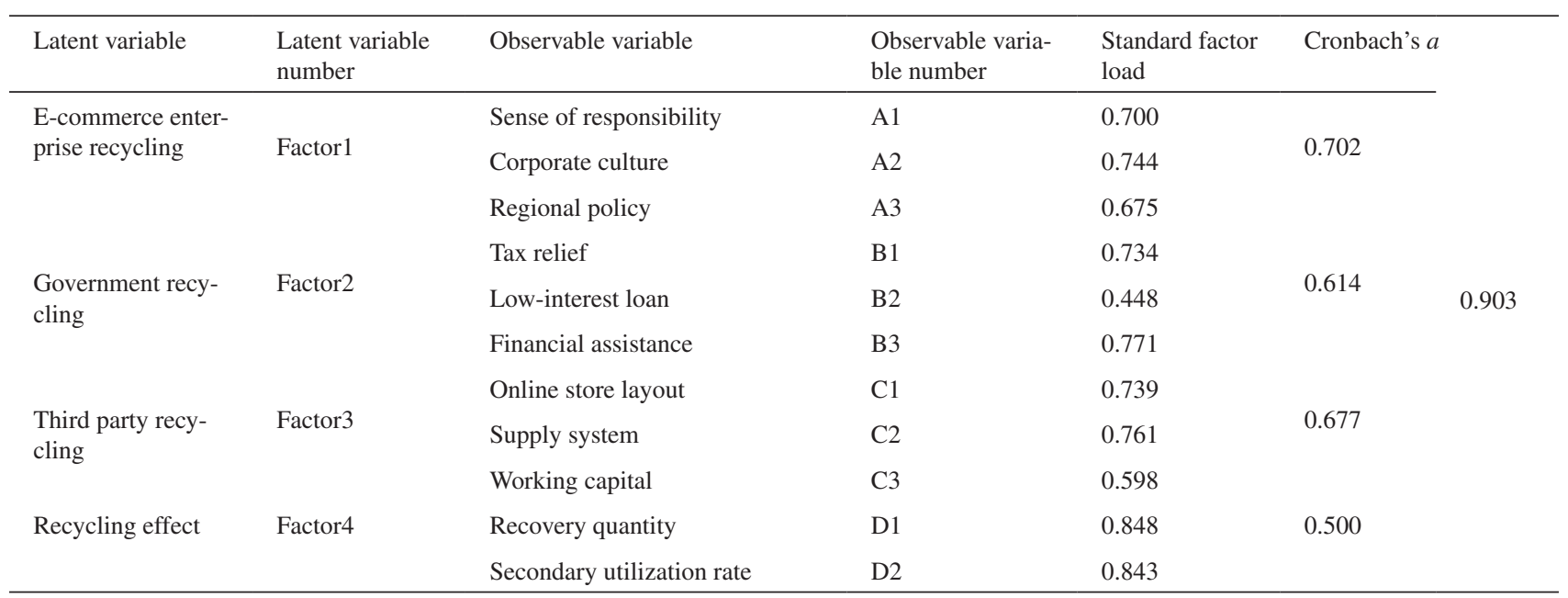


Table 3: Estimated value of the residual error term.

\begin{tabular}{lllll}
\hline Item & Nonstandard estimation coefficient & Standard error & $\mathrm{z}$ & $\mathrm{p}$ \\
\hline Factor1 & 0.473 & 0.063 & 7.466 & 0.000 \\
Factor2 & 0.732 & 0.085 & 8.640 & 0.000 \\
Factor3 & 0.653 & 0.075 & 8.667 & 0.000 \\
a1 & 0.433 & 0.039 & 11.000 & 0.000 \\
a2 & 0.418 & 0.041 & 10.078 & 0.000 \\
a3 & 0.571 & 0.054 & 10.539 & 0.000 \\
b1 & 0.418 & 0.042 & 9.855 & 0.000 \\
b2 & 0.777 & 0.061 & 12.751 & 0.000 \\
b3 & 0.500 & 0.052 & 9.694 & 0.000 \\
c1 & 0.391 & 0.037 & 10.642 & 0.000 \\
c2 & 0.744 & 0.062 & 12.039 & 0.000 \\
c3 & 0.549 & 0.047 & 11.718 & 0.000 \\
d1 & 0.470 & 0.047 & 9.994 & 0.000 \\
d2 & 0.229 & 0.039 & 5.867 & 0.000 \\
\hline
\end{tabular}

KMO value was 0.90 , which is greater than the critical value (0.7). Meanwhile, the $X$ value of the Bartlett spherical test was $2300.781(\mathrm{P}<0.001)$. Therefore, the survey data were of high correlation, indicating that they are suitable for the factor analysis.

\section{Result Analysis}

The path coefficient of SEM was calculated through Stata16.0, and the relationship between latent variables and that between latent and observable variables are illustrated in Table 4. When the e-commerce enterprises participated in the recycling, the standardized path coefficient value was 0.575 . This path presented a significance level of 0.05 $(\mathrm{z}=2.041, \mathrm{p}=0.041<0.05)$, indicating that the participation of e-commerce enterprises generated a significant positive influence on the recycling of e-commerce logistics package wastes. Government and third-party recycling generated remarkable negative and positive influences on the recycling effect, respectively.

Fig. 2 shows that the proposed $\mathrm{H} 1$ and $\mathrm{H} 3$ held true, while $\mathrm{H} 2$ did not.

(1) Hypothesis H1 was true. This study verified that the participation of e-commerce enterprises could exert an apparent positive influence on the recycling of e-commerce logistics package wastes, which was largely consistent with most previous research conclusions. E-commerce enterprises are the direct participators in the recycling of express packages. Consumers and e-commerce enterprises should be informed about logistics package recycling through a variety of channels to elicit a high level of interest and ensure express packages recycling is carried out in a timely and orderly manner. The recycling concept of express packages should be actively promoted through various channels, such as networks and news media, to raise environmental awareness among e-commerce enterprises and establish the foundation for express package recycling. E-commerce enterprises should take full utilization of online channels to recycle express packages, develop an online appointment platform, and collaborate with logistics companies in the offline collection of goods to improve the ease of recycling channels and encourage recycling behaviors.

(2) Hypothesis $\mathrm{H} 2$ was not true. This study verified that the government participation in the recycling of e-commerce logistics package wastes did not generate any practical effect, indicating that no actual recycling effect was achieved when the government served as a market subject in the recycling of logistics package wastes. To figure out the reason behind

Table 4: Model regression coefficient.

\begin{tabular}{lllllll}
\hline $\mathrm{X}$ & $->$ & $\mathrm{Y}$ & Standardization coefficient & $\mathrm{SE}$ & $\mathrm{z}$ & $\mathrm{p}$ \\
\hline Factor1 & $->$ & Factor4 & 0.575 & 0.282 & 2.041 & 0.041 \\
Factor2 & $->$ & Factor4 & -1.46 & 0.654 & -2.233 & 0.026 \\
Factor3 & $->$ & Factor4 & 1.981 & 0.657 & 3.016 & 0.003 \\
\hline
\end{tabular}




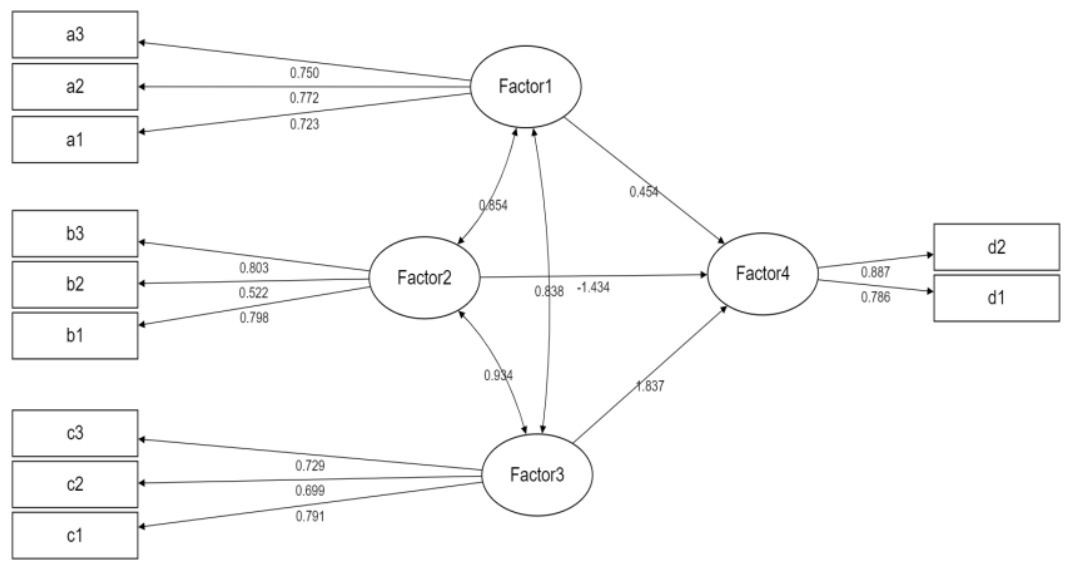

Fig. 2: Graphical SEM result.

this situation, given that the existing e-commerce enterprises are primarily concerned with the development of e-commerce platforms, basic government economic policies and self-recycling fail to completely draw the e-commerce enterprises' attention. Although the government establishes up e-commerce waste recycling platforms and provides subsidies for the recycling of e-commerce logistics packages and to enterprises for their door-to-door recycling, these measures are insufficient to encourage e-commerce enterprises to participate more actively in the recycling of logistics package wastes. At present, only a few recycling sites of e-commerce logistics package wastes can be found in many Chinese cities, all of which have poor accessibility, and residents cannot conveniently participate in the recycling process. Accordingly, it is not realistic for the government to actively undertake the subject responsibility for e-commerce waste recycling.

(3) H3: Third-party enterprises play a significant positive role in the recycling of e-commerce logistics package wastes, and the recycling effect is stronger than that achieved by e-commerce enterprises. If consumers can initiatively send the package wastes to third-party recycling sites on their own initiative, or if third-party recycling sites assign personnel to provide paid door-to-door service for the waste collection, then the recycled express package wastes will be classified by the recycling sites and differently disposed of according to the classification result. The packages that can be repeatedly used will be returned to the express companies. Those packages that can be reused after processing and treatment will be sent to the package production enterprises. The unrecyclable packages will be sent to third-party waste disposal companies for landfilling or burning. Therefore, the express package recycling systems established by third-party professional waste recycling enterprises may fully utilize their professional expertise and enable garbage disposal to reach a professional level.

\section{POLICY SUGGESTIONS}

\section{E-Commerce Enterprises Should Guide the Green Consumption Needs and Realize the Environmental Protection of Source Package}

E-commerce platforms can guide merchants to use environmentally friendly express packages through the rule negotiation or reward and punishment measures and further promote environmentally friendly e-commerce packaging. Furthermore, these platforms can provide suitable preferential treatment in settlement expense or transaction commission and impose certain punishments on merchants that do not use green packages. Besides guiding the green consumption needs of merchants, consumers' green consumption needs can also be led through some marketing means. E-commerce enterprises encourage consumers to initiatively select green packages by increasing the credit points and endowing coupons, and they can also enhance the propaganda of such marketing activities. Meanwhile, the R\&D of package production enterprises should be strengthened to increase the green supply of express packages. The package production enterprises, which are important subjects in the express package pollution control, should strengthen the sense of responsibility and concept of green development among the subjects and actively implement national rules and standards regarding the green package. Moreover, these enterprises should comprehensively assess the environmental protection property of express packaging supplies in the whole cycle, such as the source of raw materials, package production, and waste recycling. Finally, such enterprises should give full play to their guiding role in advocating rational consumption and promoting green packages. 
The Government Should Perfect the Related Laws and Regulations to Standardize Enterprises' Recycling Behaviors. The package recycling problem faced by express enterprises is a significant problem of structural optimization and transformation of the express delivery express. The Chinese government should attach importance to the overall regulation of the express delivery industry, perfect the corresponding laws and regulations with respect to the package problem, improve the utilization efficiency of express resources, and facilitate the progress and development of the express delivery industry. Related departments should promulgate express package recycling laws and form a complete normative system to ensure that the express packaging and delivery industries have laws to abide by during the operation period. When guiding and standardizing the existing express business, the government should provide supplementary explanations about the package production, use, and recycling and urge the express delivery industry to perform according to related stipulations. The government sectors should give preferential tax policies to enterprises specialized in waste recycling, develop green loan channels, enact related documents, and provide subsidies. The related government sectors should provide financial and policy support to some express package recycling enterprises to encourage their development.

\section{Establish A Third-Party Professional Recycling System and Increase the Technology Content of Recycling Work}

To improve the recycling efficiency of express packages, e-commerce enterprises should establish a professional recycling system to cover core links, such as production, recycling, and use, and realize the whole process real-time monitoring of express packaging and recycling work. Related administrative departments should unite core enterprises in the industrial chain, such as express and package production enterprises, to establish a complete recycling system and fulfil enterprise obligations. Manufacturers, users, consumers, and government administrative departments are required to undertake joint responsibilities. The professional express package recycling system should cover all persons of interest during the use period of packaging materials. After the express package system is perfected, the express enterprises can systematically carry out the express package recycling work. The recycling organizations should conduct the recycling work reasonably according to the recycling labels specified on the packaged articles. Taking package recycling into account, enterprises producing cartons should reduce the product breakage rate in the follow-up use, properly improve the carton design, and enhance the compressive strength. Packaging tapes should not be excessively used to intertwine the expressages because they make the unboxing process extremely inconvenient and result in environmental pollution.

\section{CONCLUSIONS}

China's online shopping has entered an omni-channel period, and the express delivery industry is also developed at full speed. With the high-speed growth of express business volume, the environmental destruction and waste of resources triggered by express packages have become increasingly serious, and the recycling of express packages has become a resource, environmental and social problem that remains to be urgently solved. The research hypotheses were established for the multi-subject (e-commerce enterprise, government, and third-party enterprise) participation in the recycling of e-commerce logistics package wastes. The SEM was used to empirically study the recycling effect of e-logistics package wastes with multi-subject participation. The results showed that the overall Cronbach's alpha value of the questionnaire was 0.903 , indicating good reliability. The standard factor loading coefficients of all observable variables were greater than 0.5 , manifesting satisfactory construct validity. Third-party and e-commerce enterprises generated significant positive influences on the recycling effect of e-commerce logistics package wastes, with the regression coefficients of 1.981 and 0.575 , respectively. However, the recycling effect was not affected by the government participation. The policy suggestions for the multi-subject governance and control of e-commerce logistics package wastes include the following: The e-commerce enterprises should guide the green consumption needs, and the government should perfect the related laws and regulations of e-commerce logistics packages and establish a third-party professional recycling system. This study suggests that the multi-subject governance pattern of express package pollution, public participation mechanism in the field of express package pollution control, and double-track system construction for professional express package recycling should be deeply explored.

\section{ACKNOWLEDGMENTS}

This study was sponsored by Changzhou Science and Technology Project(No. CR20202010).

\section{REFERENCES}

Aboelmaged, M. 2021. E-waste recycling behaviour: An integration of recycling habits into the theory of planned behaviour. Journal of Cleaner Production, 278: 124182.

Arain, A. L., Pummill, R., Adu-Brimpong, J., Becker, S., Green, M., Ilardi, M. and Neitzel, R. L. 2020. Analysis of e-waste recycling behavior based on survey at a Midwestern US University. Waste Management, 105: 119-127.

Bai, H., Wang, J. and Zeng, A. Z. 2018. Exploring Chinese consumers' attitude and behavior toward smartphone recycling. Journal of Cleaner Production, 188, 227-236. 
Bamberg, S. 2003. How does environmental concern influence specific environmentally related behaviors? A new answer to an old question. Journal of Environmental Psychology, 23(1): 21-32.

Feng, L., Govindan, K. and Li, C. 2017. Strategic planning: Design and coordination for dual-recycling channel reverse supply chain considering consumer behavior. European Journal of Operational Research, 260(2): 601-612.

Kelly, T. C., Mason, I. G., Leiss, M. W. and Ganesh, S. 2006. University community responses to on-campus resource recycling. Resources, Conservation and Recycling, 47(1): 42-55.

Klaiman, K., Ortega, D. L. and Garnache, C. 2016. Consumer preferences and demand for packaging material and recyclability. Resources, Conservation and Recycling, 115: 1-8.

Knussen, C. and Yule, F. 2008. I'm not in the habit of recycling, the role of habitual behavior in the disposal of household waste. Environment and Behavior, 40(5): 683-702.

Lin, C. H., Wen, L. and Tsai, Y. M. 2010. Applying decision-making tools to national e-waste recycling policy: an example of analytic hierarchy process. Waste Management, 30(5): 863-869.
Pei, Z. 2019. Roles of neighborhood ties, community attachment and local identity in residents' household waste recycling intention. Journal of Cleaner Production, 241: 118217.

Robinson, G. M. and Read, A. D. 2005. Recycling behaviour in a London Borough: Results from large-scale household surveys. Resources, Conservation and Recycling, 45(1): 70-83.

Veiga, M. M. 2013. Analysis of efficiency of waste reverse logistics for recycling. Waste Management \& Research, 31(10): 26-34.

Wang, Z., Guo, D. and Wang, X. 2016. Determinants of residents' e-waste recycling behaviour intentions: evidence from China. Journal of Cleaner Production, 137: 850-860.

Yu, T. K., Lin, F. Y., Kao, K. Y., Chao, C. M. and Yu, T. Y. 2019. An innovative environmental citizen behavior model: Recycling intention as climate change mitigation strategies. Journal of Environmental Management, 247: 499-508.

Yamaguchi, K. and Takeuchi, K. 2016. Consumer preferences for reduced packaging under economic instruments and recycling policy. Waste Management, 48: 540-547. 